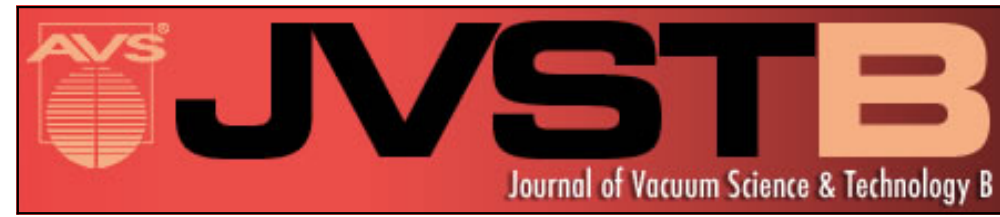

\title{
Closed-loop control of composition and temperature during the growth of InGaAs
} lattice matched to InP

S. R. Johnson, E. Grassi, M. Beaudoin, M. D. Boonzaayer, K. S. Tsakalis, and Y. H. Zhang

Citation: Journal of Vacuum Science \& Technology B 17, 1237 (1999); doi: 10.1116/1.590729

View online: http://dx.doi.org/10.1116/1.590729

View Table of Contents: http://scitation.aip.org/content/avs/journal/jvstb/17/3?ver=pdfcov

Published by the AVS: Science \& Technology of Materials, Interfaces, and Processing

\section{Articles you may be interested in}

Growth by molecular beam epitaxy of self-assembled InAs quantum dots on InAIAs and InGaAs lattice-matched to $\mathrm{InP}$

J. Vac. Sci. Technol. B 25, 1044 (2007); 10.1116/1.2731334

Closed-loop control of resonant tunneling diode barrier thickness using in situ spectroscopic ellipsometry J. Vac. Sci. Technol. B 18, 1439 (2000); 10.1116/1.591399

Real-time composition control of InAIAs grown on InP using spectroscopic ellipsometry

J. Vac. Sci. Technol. B 18, 1435 (2000); 10.1116/1.591398

In situ temperature control of molecular beam epitaxy growth using band-edge thermometry

J. Vac. Sci. Technol. B 16, 1502 (1998); 10.1116/1.589975

Real time in situ composition control of InGaAs lattice matched to InP by an 88-wavelength ellipsometer

J. Vac. Sci. Technol. B 16, 1484 (1998); 10.1116/1.589971

\section{Instruments for Advanced Science}

Contact Hiden Analytical for further details: w www.HidenAnalytical.com E info@hiden.co.uk CLICK TO VIEW our product catalogue

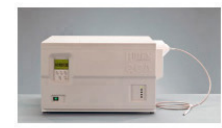

Gas Analysis

dynamic measurement of reaction gas streams catalysis and thermal analysis

molecular beam studies

, fermentation, environmental and ecological studies

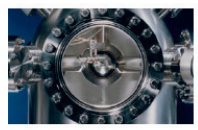

Surface Science UHVTPD , SIMS

end point detection in ion beam etch elemental imaging-surface mapping

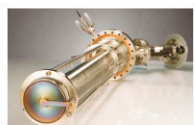

Plasma Diagnostics ; plasma source characterization etch and deposition process reaction kinetic studies , analysis of neutral and radical species

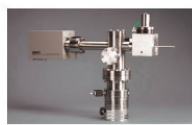

Vacuum Analysis ' partial pressure measurement and control of process gases reactive sputter process control vacuum diagnostics vacuum coating process monitoring 


\title{
Closed-loop control of composition and temperature during the growth of InGaAs lattice matched to InP
}

\author{
S. R. Johnson, ${ }^{\text {a) }}$ E. Grassi, M. Beaudoin, M. D. Boonzaayer, K. S. Tsakalis, \\ and Y. H. Zhang \\ Center for Solid State Electronics Research, Department of Electrical Engineering, \\ Arizona State University, Tempe, Arizona 85287-6206
}

(Received 5 October 1998; accepted 27 November 1998)

\begin{abstract}
Spectroscopic ellipsometry (SE) and diffuse reflection spectroscopy (DRS) are used to control the Ga mole fraction and substrate temperature, respectively, during the growth of InGaAs lattice matched to InP. Ga mole fraction is controlled to within \pm 0.002 of its target value and substrate temperature is controlled to within $\pm 2{ }^{\circ} \mathrm{C}$ of its target value. The same growth under constant thermocouple control would result in a $50{ }^{\circ} \mathrm{C}$ rise in real substrate temperature and a $\mathrm{Ga}$ composition $1 \%$ above its target value. In both cases, feedback control is achieved using a nested proportional-integral-derivative (PID) control loop, where, the inner loop consists of the conventional Eurotherm-thermocouple feedback loop and the outer loop updates the thermocouple setpoint using a PID control loop implemented in the control software. For composition control, the Ga cell thermocouple setpoint is increased (decreased) $0.2{ }^{\circ} \mathrm{C}$ for every 0.002 that the Ga mole fraction, given by the SE sensor, deviates below (above) the target value. During substrate temperature control, the thermocouple setpoint is updated based on the temperature difference between the DRS sensor and the user setpoint. Frequency loop shaping, based on a dynamical model of the system obtained from an identification experiment, is used to tune the outer PID loop.
\end{abstract}

(C) 1999 American Vacuum Society. [S0734-211X(99)01003-3]

\section{INTRODUCTION}

In situ control of group III mole fraction and substrate temperature are critical during the molecular-beam epitaxy (MBE) growth of high-quality lattice-matched InGaAs on InP. As a first step in controlling substrate temperature, an accurate reliable temperature measurement method is required. Recently several optical methods that infer substrate temperature from the band gap of the substrate material have been developed. ${ }^{1-5}$ Presently, we use diffuse reflection spectroscopy (DRS) $)^{1,2}$ to measure the band edge of InP and GaAs substrates. In this method, the substrate is illuminated by a broad spectrum W-halogen lamp placed at an effusion cell port; light that is transmitted through the substrate, diffusely reflected, and retransmitted back through the substrate, is detected at the pyrometer port. Substrate temperature is inferred from the wavelength of the onset of substrate transparency to the diffusely reflected light.

Spectroscopic ellipsometry (SE) has proven to be an accurate method for controlling near surface composition during the growth of ternary alloys. ${ }^{6-8} \mathrm{SE}$ is an optical technique that measures (over a range of wavelengths) the change in the polarization state of light, that occurs, as it reflects from the surface layer of the substrate. The change in the polarization state is related to the near surface optical functions using a virtual interface $\operatorname{model}^{8}$ and the Fresnel equations. The near surface composition is determined by comparing the measured optical functions to a previously recorded library containing the optical functions for several different compositions at various growth temperatures. Cur-

${ }^{a)}$ Electronic mail: shane.johnson@asu.edu rently, our optical function library for InGaAs comprises compositions that are within a \pm 0.03 mole fraction of the InP lattice-matched condition for growth temperatures ranging from 380 to $520^{\circ} \mathrm{C}$. We expect to publish the InGaAs database in its final form within the next year.

\section{CLOSED-LOOP CONTROL}

The nested loop approach shown in Fig. 1 is a convenient way to add accurate external sensors to the conventional Eurotherm-thermocouple control loops found in most MBE systems. In this case, the outer control loop updates the Eurotherm (thermocouple) setpoint based on the difference between the user setpoint and the value measured by the external sensor, using a proportional-integral-derivative (PID) algorithm implemented in control software. This method has the advantage that the Eurotherm-thermocouple control system is left intact, so that, in the event that the external sensor or control computer fail, the heater power will continue to be controlled.

The first (upper) nested control loop shown in Fig. 1, controls substrate temperature using DRS as the external sensor. The second (lower) loop shown, controls composition using SE as the external sensor. Both control loops are similar in that the Eurotherm-thermocouple (or inner) loop primarily controls the heating element and is limited in its ability to detect and control either true substrate temperature ${ }^{1}$ or true group III deposition rates. ${ }^{9}$ This inability also means that the Eurotherm-thermocouple control loop only partially rejects external disturbances, such as the thermal-shutter transients that occur in effusion cells and at the substrate when effusion cell shutters are toggled. In this control 

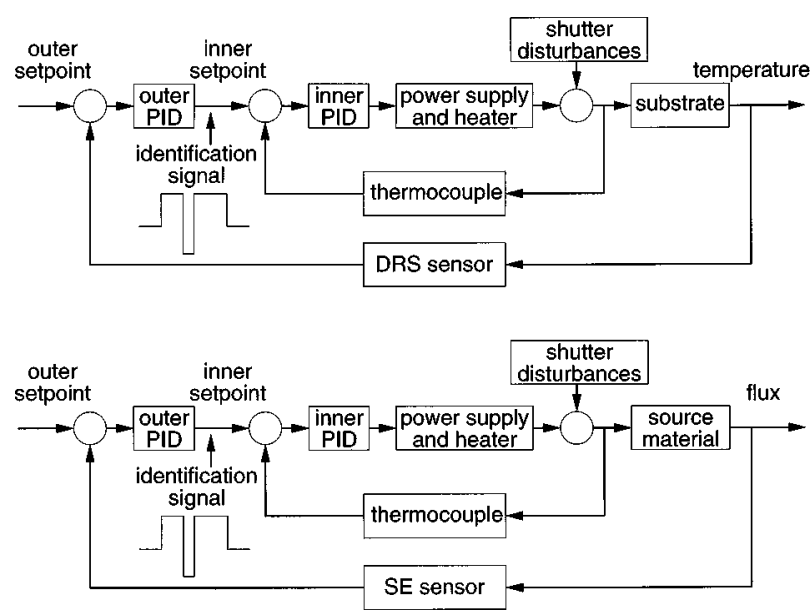

FIG. 1. Schematic of the nested proportional-integral-derivative (PID) control loops used to control substrate temperature (upper sketch) and composition (lower sketch). In both cases, the inner loop is the conventional Eurotherm-thermocouple control loop. The outer loop updates the inner loop setpoint based on the difference between the outer loop setpoint and, the substrate temperature measured by diffuse reflectance spectroscopy (DRS), or the Ga mole fraction measured by spectroscopic ellipsometry (SE).

scheme, the outer loop periodically updates the thermocouple setpoint, causing the Eurotherm control loop to bring substrate temperature or effusion cell flux back in line with its target value.

The parameters relating to substrate temperature and composition during the growth of lattice-matched InGaAs on a radiatively heated $50 \mathrm{~mm}$ semi-insulating $\mathrm{InP}$ substrate, are shown in Figs. 2 and 3. In both figures, growth time and layer thickness are shown on the lower and upper horizontal axis, respectively. The growth starts at zero minutes and ends at $58.3 \mathrm{~min}$, for a total layer thickness of $400 \mathrm{~nm}$. This material was grown in a DCA MBE system, that has the unique ability to minimize substrate wobble, in situ, using three piezo crystals that individually adjust the length of three ma-

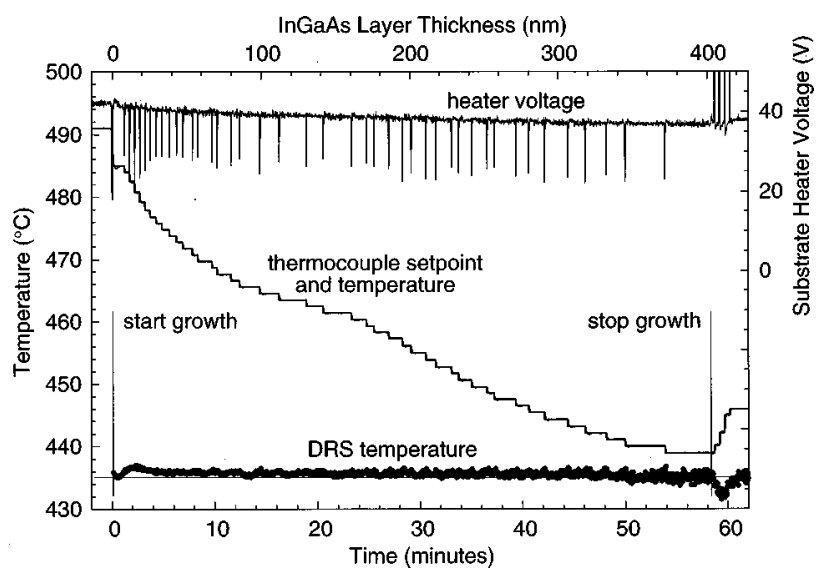

FIG. 2. Closed-loop control of substrate temperature during the growth of lattice-matched InGaAs on semi-insulating InP, using diffuse reflectance spectroscopy (DRS). Substrate setpoint $\left(435^{\circ} \mathrm{C}\right)$, DRS temperature, thermocouple temperature and setpoint, and heater voltage (at power supply) are shown.

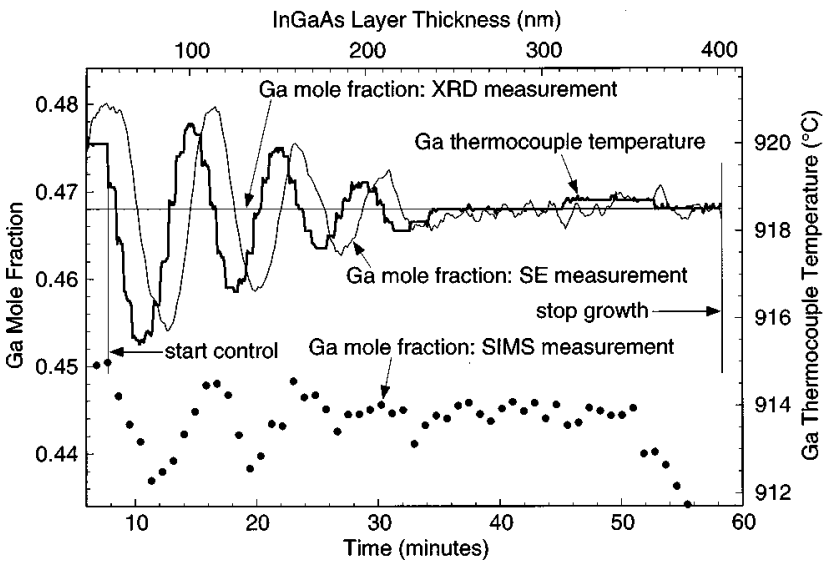

FIG. 3. Closed-loop control of Ga mole fraction during the growth of $\mathrm{In}_{0.532} \mathrm{Ga}_{0.468} \mathrm{As}$ on InP, using spectroscopic ellipsometry (SE). The Ga mole fraction given by, SE, secondary ion mass spectrometry (SIMS), and x-ray diffraction (XRD), and the Ga cell thermocouple temperature are shown.

nipulator support rods. ${ }^{10}$ Both substrate temperature and Ga mole fraction were controlled using the control scheme and sensors shown in Fig. 1.

Substrate (DRS) temperature, thermocouple temperature, and heater voltage recorded during the growth of this layer are shown in Fig. 2. The supervisory computer samples the DRS temperature every $30 \mathrm{~s}$, if the DRS temperature has deviated more than $\pm 1{ }^{\circ} \mathrm{C}$ from the substrate setpoint of $435^{\circ} \mathrm{C}$, the outer PID loop updates the Eurotherm (inner) setpoint. Throughout most of the growth of the InGaAs layer, the substrate temperature is about $1{ }^{\circ} \mathrm{C}$ above its setpoint. Decreasing the update time would bring the substrate temperature closer to the setpoint during the first part of the growth. As can be seen in Fig. 2, each time the thermocouple setpoint is updated, there is a sharp drop in the heater voltage and the thermocouple temperature quickly moves to its new setpoint. The thermal response of the thermocouple-heater system is fast (4 s time constant) compared to the thermal response of the substrate (60 s time constant); this allows appropriate control action.

Radiatively heated substrates are known to heat up dramatically during the growth of absorbing overlayers, such as near-lattice-matched InGaAs on InP, when constant thermocouple control is used. ${ }^{11,12}$ In this case, the thermocouple is insensitive to the substrate temperature increase caused by the strong absorption of heater radiation in the overlayer. The small-band gap epilayer absorbs a larger part of the heater radiation spectrum than the InP substrate, which is transparent to much of the blackbody spectrum at these temperatures. Therefore, as the InGaAs layer thickens, the transmission losses of heater radiation are reduced. In order to maintain constant substrate temperature, the control system continually reduces the heater power by decreasing the Eurotherm (thermocouple) setpoint over the course of the growth.

The small oscillations in the substrate temperature at the start and stop points are caused by the abrupt changes in the thermal load on the substrate when the In and Ga cells are 
toggled. At the start of growth the thermocouple setpoint is reduced by $6{ }^{\circ} \mathrm{C}$ in an effort to correct for the thermal disturbance caused by additional radiant heat load of the In and $\mathrm{Ga}$ effusion cells. This is the simplest way of rejecting thermal disturbances. At the end of the growth, no shutter disturbance rejection is used and the substrate momentarily drops $4{ }^{\circ} \mathrm{C}$ below the setpoint. A more sophisticated approach to disturbance rejection is discussed in the following section.

The Ga mole fraction, as measured by SE, secondary ion mass spectroscopy (SIMS), and x-ray diffraction (XRD), and the $\mathrm{Ga}$ cell thermocouple temperature, for the InGaAs growth, are shown in Fig. 3. The supervisory computer samples the Ga mole fraction given by the SE computer ${ }^{8}$ every $30 \mathrm{~s}$, if the mole fraction has deviated more than \pm 0.002 from the 0.468 target value, the outer PID loop updates the Eurotherm (inner) setpoint. When the outer loop gain is one, the setpoint change is $\mp 0.2{ }^{\circ} \mathrm{C}$ for every \pm 0.002 deviation in $\mathrm{Ga}$ mole fraction. The thermal response of the thermocouple-cell heater system is fast (6 s time constant) compared to the thermal response of the Ga melt (45 s time constant); again, this allows appropriate control action.

We have found that SE cannot accurately determine the composition of thin InGaAs layers, most likely, because the thin layer optical functions differ from those of the bulk material. Consequently, the extraction of composition from SE data is not initiated until $6.0 \mathrm{~min}$ (or $41 \mathrm{~nm}$ ) into the growth and composition control is not initiated until $7.7 \mathrm{~min}$ (or $53 \mathrm{~nm}$ ) into the growth. At the start of control, the Ga cell temperature is $920.0{ }^{\circ} \mathrm{C}$ and GA mole fraction is 0.480 , at which time the outer control loop decreases the Ga cell temperature. The initial $\mathrm{Ga}$ and In effusion cell settings, for the lattice matched condition, were estimated from previous growths of near-lattice-matched InGaAs. In this particular run the outer loop PID parameters were not well tuned and the Ga cell temperature and mole fraction oscillated for 25 min before stabilizing.

Though not well tuned, this experiment is a good illustration of the type of dynamics that occur within the effusion cell and the sensors in the closed-loop control system. The oscillations in the Ga cell flux lag those of the Ga cell temperature by $1.7 \mathrm{~min}\left(90^{\circ}\right.$ phase lag). This occurs because the Ga melt responds much more slowly to the heater than the thermocouple. This is an important consideration for anyone growing graded layers using dead reckoning thermocouple control. The GA cell temperature stabilized at $918.5^{\circ} \mathrm{C}$, which corresponds to the lattice matched condition. If grown using dead reckoning, the resulting Ga mole fraction would be about $1 \%$ too high for this run. The nice clear oscillations in the Ga mole fraction measured by SE, indicate that $\mathrm{SE}$ is a reliable sensor of the near surface composition of InGaAs.

The InGaAs composition was measured using XRD and found to be lattice matched to InP, within the resolution of the XRD measurement, which in mole fraction, is \pm 0.001 . The lattice matched mole fractions are given as $\mathrm{In}_{0.532} \mathrm{Ga}_{0.468} \mathrm{As},{ }^{13}$ as suggested by Vegard's law. The XRD measurement gives an average composition for the InGaAs

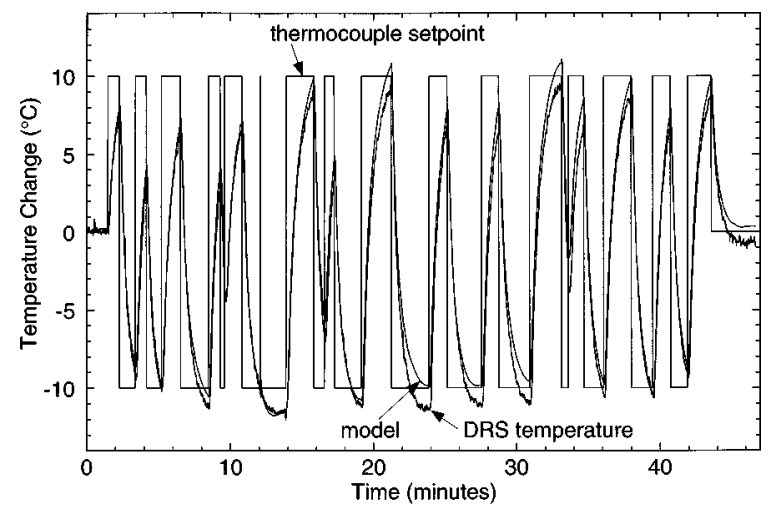

FIG. 4. Identification experiment used to determine the state space model that relates heater voltage to substrate temperature. The identification signal (Eurotherm thermocouple setpoint), substrate temperature measured by diffuse reflectance spectroscopy (DRS), and substrate temperature predicted by the model, are shown.

layer and is shown by the solid horizontal line at $0.468 \mathrm{Ga}$ mole fraction. The Ga mole fraction given by the SIMS measurement is about 0.025 too low, however, it does verify the oscillations seen by SE. The drop in the SIMS data at the surface of the sample is due to surface effects.

\section{OUTER LOOP TUNING}

In order to improve the closed-loop control of substrate temperature and composition, the outer PID is tuned using frequency loop shaping (FLS), ${ }^{14}$ which attempts to approximate in a minimax sense the loop transfer function of the system to a desired one in the frequency domain. The ideal loop transfer function is selected, based on stability and performance considerations, and on the characteristics of the system. FLS requires a model of the system (in the frequency domain); this model can be obtained using standard systems identification techniques.

As a first step, an input signal is designed that covers the frequency range of interest. Next, the temperature of the substrate is brought to, and allowed to stabilize at, the desired operating point. With the external (outer) control loop open, the identification signal is applied at the Eurotherm (inner) setpoint (see Fig. 1), while the external sensor measurements are collected. Using the method described in Ref. 15, a state space model is found, ${ }^{16}$ that describes the dynamic behavior of the system from the power supply input to the external sensor measurement. (A state space model is a set of forced linear ordinary differential equations.) The DRS temperature, the temperature predicted by the model, and the identification signal are shown in Fig. 4. A second order state space model was used to identify the system. The model was verified using a separate data set.

The desired time constant of the controlled system is about $15 \mathrm{~s}$. Therefore, we need to obtain a model of the system around the frequency, 1/15 rad/s. The input signal for the identification experiment is a random-switching binary signal with levels of $\pm 10^{\circ} \mathrm{C}$ around the desired operating point. The switching time is uniformly distributed over $1-160 \mathrm{~s}$, with a mean of $80 \mathrm{~s}$. Since the sampling interval is 
$1 \mathrm{~s}$, the maximum frequency spanned is $1 \mathrm{~Hz}$. This is adequate for our goals. The frequency resolution is $1 / \mathrm{N} \mathrm{Hz}$, where $N$ is the number of data points collected. Usually a resolution of 1/30 of the closed loop bandwidth is enough for this type of system where no sharp resonant peaks are present.

The PID parameters obtained with FLS are very different from those obtained with the traditional step response PID tuning method (Ziegler-Nichols method 1). ${ }^{16}$ The ZieglerNichols rule gives $\left[K_{p}, T_{i}, T_{d}\right]=[8.4,12 \mathrm{~s}, 3.0 \mathrm{~s}]$, while FLS gives $\left[K_{p}, T_{i}, T_{d}\right]=[2.1,34 \mathrm{~s}, 0.7 \mathrm{~s}]$, for the outer substrate temperature control loop. The Ziegler-Nichols method approximates the system by a first order model with delay, and is only applicable for "s" shaped step responses (see Ref. 16). As can be seen in Fig. 4, the lag in the step response (6 s) is very short compared with the rise time ( $42 \mathrm{~s}$ ), which makes the Ziegler-Nichols rules inappropriate for the present system. Using the Ziegler-Nichols rule to tune the outer substrate temperature control loop results in a closed loop system that is unstable. Since the Ga effusion cell identification experiments and modeling of the dynamics are currently in progress, we are unable to report the PID parameters given by FLS for the Ga cell.

During the growth of thick absorbing overlayers, the absorption-emission properties of the substrate-epilayer system change considerably. This means that in general, the optimal PID parameters would change accordingly and several PIDs would have to be scheduled. Gain scheduling was not used in the growth shown in Fig. 2; in this case a single set of PID parameters was sufficient to control temperature. Finally, the DRS signal is reduced when an absorbing layer is present, as can be seen by an increase in the noise of the DRS data in Fig. 2. Since the data acquisition frequency of the DRS data is much larger than that of the control system, much of the noise in the DRS data is removed at the DRS sensor input, using a low pass filter.

Another important control objective is good temperature regulation during external disturbances, such as thermal shutter transients. Since it is precisely known when each effusion cell shutter is toggled, control algorithms that take preventive action can be used to correct for the thermal transients that may occur at the substrate or in the effusion cell melt. Identification experiments similar to the one described above can be used to model the disturbance signal associated with shutter operations. Based on the inverse model, corrective action in the form of a time dependent signal added at the Eurotherm (inner) setpoint can be used to reject the disturbance. This time dependent signal takes into account the dynamics of the system, which are not included in the simple step adjustment used in Fig. 2. Inclusion of the system dynamics will be most visible in cases where the substrate or melt response lags the shutter disturbance.

\section{CONCLUSIONS}

A nested proportional-integral-derivative control loop is used to achieve closed-loop control of substrate temperature and $\mathrm{Ga}$ mole fraction during the growth of lattice-matched InGaAs on InP, to within $\pm 2{ }^{\circ} \mathrm{C}$ and \pm 0.002 of the user specified setpoints, respectively. Diffuse reflection spectroscopy is used as an external sensor for substrate temperature and spectroscopic ellipsometry is used as an external sensor for near surface InGaAs composition. The outer loop controls the inner loop (thermocouple) setpoint, using information supplied by the external sensor. The inner loop is the standard Eurotherm-thermocouple control loop found on most MBE systems. A system identification experiment and frequency loop shaping are used to optimally tune the PID parameters of the outer control loop for substrate temperature.

\section{ACKNOWLEDGMENTS}

This work is part of a DARPA-funded program entitled "Integrated MultiSensor Control of Molecular Beam Epitaxy," under Grant No. MDA972-95-1-0016, monitored by Lt. Col. Gernot S. Pomrenke, which is a collaborative effort between scientists from HRL Laboratories, the J. A. Woollam Company, Arizona State University, and the University of Colorado.

${ }^{1}$ S. R. Johnson, C. Lavoie, T. Tiedje, and J. A. Mackenzie, J. Vac. Sci. Technol. B 11, 1007 (1993).

${ }^{2}$ S. R. Johnson, C. Lavoie, M. K. Nissen, and T. Tiedje, U.S. Patent No. 5,388,909 (1995).

${ }^{3}$ J. A. Roth, T. J. DeLyon, and M. E. Adel, Mater. Res. Soc. Symp. Proc. 324, 353 (1994).

${ }^{4}$ E. S. Hellman and J. S. Harris, J. Cryst. Growth 81, 38 (1987).

${ }^{5}$ D. M. Kirillov and R. A. Powell, U.S. Patent No. 5,118,200 (1992).

${ }^{6}$ D. E. Aspnes, W. E. Quinn, M. C. Tamargo, M. A. A. Pudensi, S. A. Schwarz, M. J. S. P. Brasil, R. E. Nahory, and S. Gregory, Appl. Phys. Lett. 60, 1244 (1992).

${ }^{7}$ C.-H. Kuo, M. D. Boonzaayer, M. DeHerrera, T. Kyong, and Y.-H. Zhang, J. Vac. Sci. Technol. B 16, 1007 (1998).

${ }^{8}$ The SE hardware and data analysis software are described in: B. Johs, J. Hale, C. Herzinger, D. Doctor, K. Elliott, G. Olson, D. Chow, J. Roth, I. Ferguson, M. Pelczynski, C.-H. Kuo, and S. R. Johnson, Mater. Res. Soc. Symp. Proc. 502, 3 (1998).

${ }^{9}$ K. G. Eyink, J. K. Patterson, S. J. Adams, T. W. Haas, and W. V. Lampert, J. Cryst. Growth 175/176, 262 (1997).

${ }^{10}$ C.-H. Kuo, M. D. Boonzaayer, M. F. DeHerrera, D. K. Schroder, G. N. Maracas, and B. Johs, J. Cryst. Growth 175/176, 281 (1997).

${ }^{11}$ B. V. Shanabrook, J. R. Waterman, J. L. Davis, and R. J. Wagner, Appl. Phys. Lett. 61, 2338 (1992).

${ }^{12}$ J. A. Roth, Mater. Res. Soc. Symp. Proc. 502, 97 (1998).

${ }^{13} \mathrm{~S}$. Adachi, Physical Properties of III-V Semiconductor Compounds, InP, InAs, GaAs, GaP, InGaAs, and InGaAsP (Wiley, New York, 1992).

${ }^{14}$ E. Grassi and K. S. Tsakalis, Proceedings of the 35th CDC, Kobe, Japan, Dec. 1996 (unpublished), pp. 4776-4781.

${ }^{15} \mathrm{~K}$. Tsakalis and K. Stoddard, Proceedings of the 6th IEEE International ETFA Conference, Los Angeles, CA, Sept. 1997 (unpublished), pp. 514519.

${ }^{16}$ K. Ogata, Modern Control Engineering, third ed. (Prentice-Hall, Englewood Cliffs, NJ, 1997), p. 670 